\title{
Epidemiology of Flavescence Dorée in Vineyards in Northwestern Italy
}

\author{
C. Morone, M. Boveri, S. Giosuè, P. Gotta, V. Rossi, I. Scapin, and C. Marzachì
}

First, fourth, and sixth authors: Regione Piemonte, Settore Fitosanitario, Via Livorno, 60, I-10144 Torino, Italy; second author: Cadir-Lab, Strada Alessandria, 13, I-15044 Quargnento (AL), Italy; third and fifth authors: Istituto di Entomologia e Patologia vegetale - Università Cattolica S. Cuore, Via Emilia Parmense 84 - I-29100 Piacenza, Italy; and seventh author: Istituto di Virologia vegetale, CNR, Strada delle Cacce, 73, I-10135 Torino, Italy.

Accepted for publication 6 June 2007.

\begin{abstract}
Morone, C., Boveri, M., Giosuè, S., Gotta, P., Rossi, V., Scapin, I., and Marzachì, C. 2007. Epidemiology of flavescence dorée in vineyards in northwestern Italy. Phytopathology 97:1422-1427.

A serious outbreak of flavescence dorée (FD) was reported in Piemonte, northwestern Italy, in 1998, and since then, the disease has compromised the economy of this traditional wine-growing area, even following the application of compulsory insecticide treatments to control Scaphoideus titanus, the vector of the causal phytoplasma. Affected vines show severe symptoms, varying according to the cultivar, and are rogued to reduce disease spread. Following winter and pruning, a previously affected vine may appear symptomless and free of phytoplasmas in its

ered plants productivity, presence of vectors, and treatment schedules have been collected in seven severely affected vineyards of southern Piemonte for 5 years (1999 to 2003). Infectivity and recovery rates were also calculated each year. From 1999 to 2003 , the average number of healthy plants decreased and the numbers of recovered plants and those with symptoms increased. Productivity of recovered vines, although lower than that of healthy ones, was always higher than that of vines with symptoms and was not influenced by the time elapsed from date of recovery. The relationships between the ln-transformed number of vectors trapped in the vineyards the previous year and the infection and the recovery rates were fitted by an exponential $\left(R^{2}=0.95\right)$ and an asymptotic $\left(R^{2}=0.93\right)$ model, respectively.
\end{abstract} aerial as well as its root system, even by nested-polymerase chain reaction assays. Such plants are considered to be "recovered". Since 1998 homogenous data on the incidence of newly infected, healthy, or recov-
Additional keywords: grapevine, phytoplasma, Scaphoideus titanus.
Flavescence dorée (FD) is an economically important quarantine disease of grapevine in Europe. It is caused by different strains of a phytoplasma belonging to the $16 \mathrm{~S}$ ribosomal group $\mathrm{V}$ (2). FD in Italy was first reported in 1973 (4) and it is mainly caused by phytoplasmas (FDPs) belonging to ribosomal subgroups $\mathrm{C}$ and D (21). Both types of FDP are vectored in nature by the leafhopper Scaphoideus titanus Ball $(8,25,33)$. Phytoplasma infection has a negative effect on the fitness of the experimental vector Euscelidius variegatus Kirschbaum (6), while possible effects on the natural vector have not been studied.

Infected grapevines usually show symptoms the year after inoculation, but according to the variety and possibly the age of the plant, longer latencies have been reported (10). Yellowing, downward curling of leaves, fruit abortion, stunting, and lack of lignification of new shoots are among the most important symptoms $(8,9)$. Following the first year of symptom expression, the successive development of the disease may vary according to the grapevine cultivar. A spontaneous remission of symptoms (recovery) may occur and the recovered plant may remain asymptomatic if not exposed to infective vectors (10). Recovery, associated or not to the absence of the phytoplasma from the host, has also been reported in fruit trees affected with different phytoplasmas $(26,27)$ and it is influenced by the pathogen and host genotypes as well as environmental conditions (13).

The epidemiology of FD has mainly been studied in France, where the disease was first reported in 1957 (7) and where it has

Corresponding author: C. Marzachì; E-mail address: c.marzachi@ivv.cnr.it

doi:10.1094/PHYTO-97-11-1422

(c) 2007 The American Phytopathological Society been a serious threat ever since. Phytoplasmas of different ribosomal subgroups are the causal agents of FD in France and northwestern Italy (21).

FDP-C was detected in most of the symptomatic grapevines and $S$. titanus individuals assayed during an epidemic of the disease in 1998 in the wine-growing area of Piemonte, northwestern Italy $(23,24)$. Yellows diseases were already known in the region (1) but were associated with the presence of Bois Noir and/or 'Candidatus phytoplasma asteris' strains. These phytoplasmas were present in some symptomatic grapevines in Piemonte both in single and mixed infections with FDP (24).

Since 1998, the regional extension services have closely monitored the epidemics and the Plant Protection Service has instigated compulsory insecticide treatments to control the vector population. This has led to the availability of homogeneous data for many vineyards on disease incidence, vector population, productivity, and treatment schedules under farming conditions from 1998 to 2003 . The current study was able to take advantage of the opportunity to evaluate the epidemiology of FD over 5 years in one of the most economically important wine-producing areas of Italy and also to provide clues for further disease management. Because the disease was wide spread in the entire region and because of its quarantine status, experimental controls were not possible, and therefore, only vineyards located in a very homogeneous area have been considered.

\section{MATERIALS AND METHODS}

Plant material. In 1998, seven severely FD-affected vineyards were chosen in a typical wine area of southern Piemonte (District of Alessandria). Three vineyards were planted with 'Dolcetto', 
two with 'Barbera', and one each with 'Bonarda' and 'Cortese'. The eldest vineyard was planted in 1982 and the youngest in 1996. The vines were regularly pruned each winter. In the fall of 1998, approximately 200 contiguous grapevines were labeled in each of the chosen vineyards. At the same time, the tagged grapevines were visually screened for FD symptoms. From 1999 to 2003, the tagged vines were observed twice a year (June and September) and classified into three categories: with FD symptoms; with a recovered phenotype (plants with disease symptoms at least once in the previous years but not affected in the current year); and healthy (disease symptoms never observed). The number of healthy fruit clusters per plant was also recorded each year at harvest time.

Total DNA extraction and phytoplasma identification. In 1999 , the presence and characterization of phytoplasmas in the symptomatic grapevines was assessed by molecular diagnosis in one to three tagged plants of each vineyard. Total DNA was extracted from $1.5 \mathrm{~g}$ of leaf veins following a phytoplasma enrichment protocol (22) and resuspended in $100 \mu \mathrm{l}$ of sterile double distilled water (SDW). Total DNA was also extracted from healthy grapevine seedlings. Universal primers, P1/P7, were used in direct polymerase chain reaction (PCR) assays as detailed by Schneider et al. (32). Reaction products were diluted 1:40 in SDW and used as templates in nested reactions driven by primers R16(I)F1/R1 or R16(V)F1/R1 for the specific diagnosis of $16 \mathrm{~S}$ groups I and V, respectively (15). Reaction and cycling conditions were as detailed in the original papers. Amplicons were separated by electrophoresis in $1 \%$ agarose gels buffered in $0.5 \times$ TBE (Trisborate-EDTA) and visualized under UV-light after staining with ethidium bromide. Fragments amplified with R16(I)F1/R1 or $\mathrm{R} 16(\mathrm{~V}) \mathrm{F} 1 / \mathrm{R} 1$ primers were digested (2- $\mu \mathrm{l}$ aliquots), according to the manufacturer's recommendations, for $2 \mathrm{~h}$ with one unit of MseI (Invitrogen, Carlsbad, CA) at $37^{\circ} \mathrm{C}$ or TaqI (Invitrogen) at $65^{\circ} \mathrm{C}$, respectively. Digestion products were separated in $5 \%$ polyacrylamide gels buffered in $1 \times \mathrm{TBE}$ along with a $1 \mathrm{~kb}$ plus DNA size marker (Gibco BRL, Paisley, UK) and visualized by UV-light after staining with ethidium bromide. Beginning in 2001, total DNA was extracted in July each year from the same grapevines to confirm FD infection. The presence or absence of phytoplasma-specific symptoms was also recorded each year and when the plant showed localized symptoms, total DNA was extracted separately from symptomatic as well as symptomless parts of the canopy.

Insect material. Starting from 1999, insecticides were applied in each vineyard to control $S$. titanus as follows: treatment within the first 10 days of June with flufenoxuron, buprofezin, or chlorpyrifos ethyl; followed by treatment before the end of July with chlorpyrifos ethyl, etofenprox, or fenitrothion. Each year, starting from 1999, the population of S. titanus was monitored with two yellow sticky traps placed in each vineyard beginning from the last 10 days of June; traps were changed every 15 days until the end of September and then checked for presence of $S$. titanus. Insects were counted and expressed as total number of trappings.

Data analysis. Yields from healthy, recovered, and symptomatic plants were calculated each year as the number of healthy clusters in each category divided by the number of plants in each category in the same year. Every year, the plants showing a recovered phenotype were classified according to the length of their recovery ( 1 to 5 years). The yield of every class was also analyzed as above.

First, we used two-way analysis of variance (ANOVA) to detect differences among years and vineyards in the number of healthy, affected, and recovered plants with the ANOVA-2 procedure of MSTAT-C (version 1.3, Michigan State University, East Lansing), which allows computation when only one observation exists for each combination of levels in two variables. The numbers of $S$. titanus trapped each year in the seven vineyards were lntransformed to make variances homogeneous for a two-way
ANOVA to detect significant differences among years and vineyards.

A factorial ANOVA was applied to test the effects of year (from 1999 and 2003) and plant categories (healthy, affected the current year, and recovered) on yield. Significant effects and interaction were further analyzed using the SNK test at $P \leq 0.05$. To evaluate the effects of recovery duration and assessment year on grape yield, a two-way ANOVA was applied with the ANOVA-2 procedure described above.

Several indexes were calculated from the original data set and analyzed using the regression procedures of SPSS (version 11.5; SPSS Inc., Chicago, IL) to find significant relationships useful for the description of disease development and explain epidemiological aspects.

The average number of newly affected plants was calculated each year and summed over the whole period of observation. Infection rate was obtained by dividing the number of newly affected plants the current year by the total number of plants showing symptoms at least once in the pervious period (total affected plants). The relationship of the infection rate over the whole period was described by a power model according to the following equation:

$$
y=a \cdot x^{b}
$$

where $y=$ infection rate; $x=$ year; and $a$ and $b=$ equation parameters.

To study the relationship between infection rate and the logarithmic transformation of the average number of $S$. titanus trapped in the vineyards the year before, we had to estimate the number of S. titanus that would have been trapped in 1998 since this was not measured. The estimate was based on the figures for 1999 by taking into account the reduction efficiency of the insecticide treatments applied in that year. The estimate for 1998 was then lntransformed. The data obtained were fitted by an exponential model in the form

$$
y=e^{(a+b \cdot x)}
$$

where $y=$ infection rate; $x=\log$ transformation of the number of trapped $S$. titanus; and $a$ and $b=$ equation parameters.

The average number of recovered plants was calculated each year as well as the average number of plants showing symptoms at least once in the period 1999 to 2003 . The recovery rate was calculated by dividing the average number of recovered plants by the average number of plants affected once in the years before the assessment. The relationship of the recovery rate during the period of observation was fitted by an asymptotic model, according to the equation:

$$
y=a-\left(b \cdot c^{x}\right)
$$

where $y=$ recovered plants; $x=$ year; and $a, b$, and $c=$ equation parameters.

The relationship between the recovery rate and the logarithmic transformation of the number of $S$. titanus trapped in the vineyards the year before was fitted by a logistic model in the form

$$
y=\frac{c}{\left[1+e^{(a-b \cdot x)}\right]}
$$

where $y=$ recovery rate; $x=\log$ transformed number of trapped $S$. titanus; and $a, b$, and $c=$ equation parameters.

The above models were chosen on the basis of both data plots and theoretical considerations (11) to take the length of the incubation period into account. The fit of the models to the experimental data was evaluated through regression analysis of variance, standard errors of parameters, coefficient of determina- 
tion $\left(R^{2}\right)$, and the distribution of residuals against the independent variable. Pearson correlation coefficients were calculated to test the association between the infection rate observed each year and the number of $S$. titanus trapped the years before.

\section{RESULTS}

FD diagnosis. PCR analysis gave a very high correspondence with FD symptoms in the 14 vines tested from 1999 to 2003 . No symptomless sample of 57 was positive. All 14 symptomatic vines tested in 1999 were PCR positive. In 2000, five of six still symptomatic vines were positive and all 13 symptomless samples were negative. For 2001, five of seven symptomatic samples were positive, with four of four positive in 2002, and one of two positive in 2003. The negative PCR results from symptomatic samples were from three vines that carried both symptomless main branches (always PCR negative) and symptomatic branches.

Bois noir (BN) phytoplasma was never detected by PCR. No phytoplasma-specific amplicon was obtained when total DNA from healthy grapevine seedlings was tested.

Restriction polymorphism analysis with $T a q \mathrm{I}$ of $16 \mathrm{Sr}(\mathrm{V}) \mathrm{F} 1 / \mathrm{R} 1$ (15) amplicons from FD-infected grapevines showed that all samples shared the same profile as FD-C, the Piemonte strain (data not shown).

FD relationships, yield, and vector populations in the seven vineyards. ANOVA showed no significant differences in the
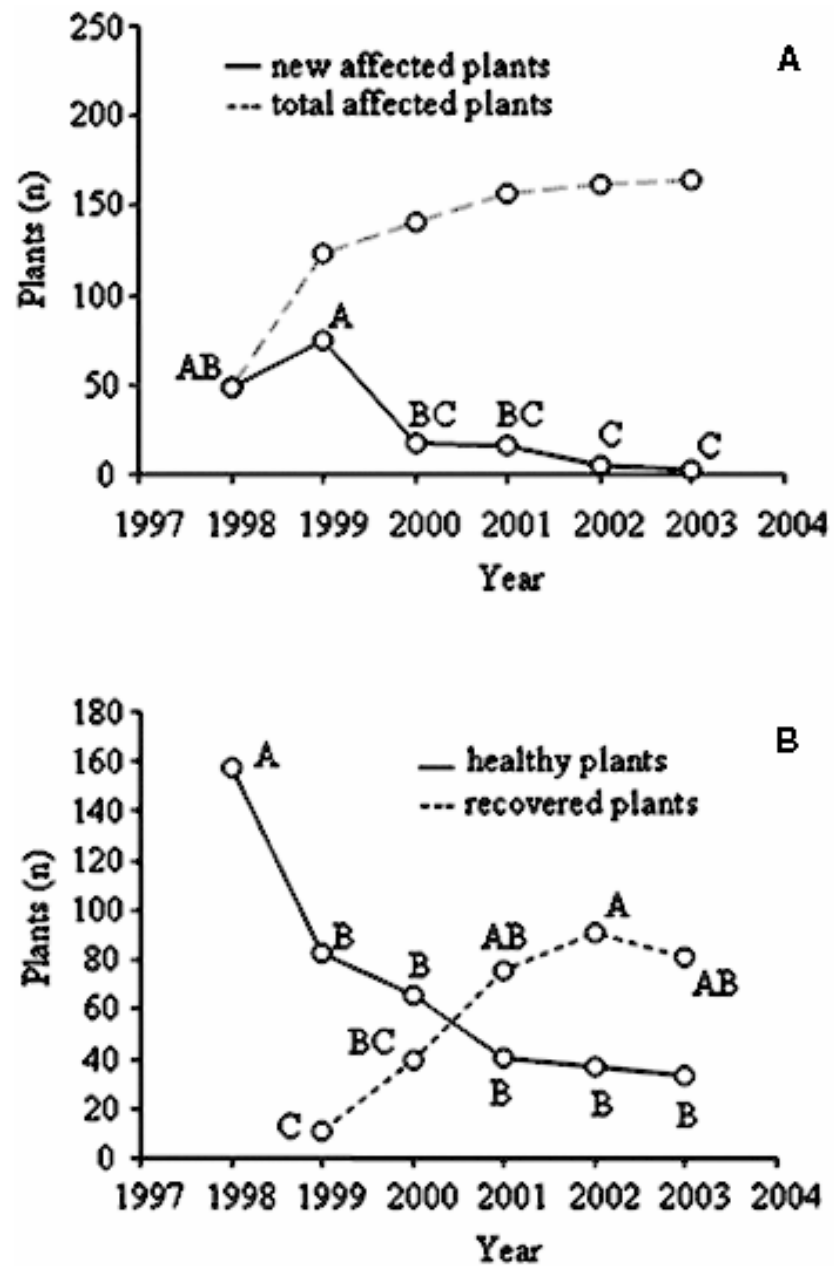

Fig. 1. A, Relationship of newly affected (solid line) and total affected (dotted line) grapevines calculated as a summation from 1998 to 2003 of the newly affected plants during the period of observation. B, Relationship of the number of healthy (solid line) and recovered plants (dotted line) from 1999 to 2003. Same letters indicate average values not significantly different according to the Tukey test at $P=0.05$. number of newly affected, healthy, or recovered plants among the vineyards within years $(P=0.131)$, and therefore, the seven observed vineyards were considered as replicates for further analyses.

The average number of healthy, affected, and recovered plants changed significantly from year to year $(P<0.001)$. The average number of newly affected plants increased from 1998 to 1999 (from 48 to 75 ), then significantly decreased in 2000 to 17 (Fig. 1A), while the small constant decrease from 2000 to 2003 was not significant. The average number of healthy plants constantly and significantly decreased from 1998 (158 plants) to 2003 (33 plants), although the decrease observed between 1999 and 2003 was not significant (Fig. 1B). The average total number of affected plants (including those infected in the previous years), increased from approximately 50 in 1998 to approximately 112 in 1999, then decreased to 49 in 2002 and 50 in 2003 (Fig. 1A). The average number of recovered plants increased from 10 in 1999 to 40 in 2000, 76 in 2001, and 91 in 2002, decreasing, though not significantly, in 2003 to 81 (Fig. 1B).

Two-way ANOVA did not show significant differences in the yield of the seven vineyards, and therefore, they were considered as replicates in a factorial ANOVA applied to verify the effects of years and category of plants on grapevine productivity. The yield of the plants belonging to the three categories every year is shown in Table 1 . Within each category, the yield was not significantly different among years, while the yield of healthy, affected, and recovered grapevines was significantly different: the highest number of clusters per plant was observed on healthy plants (approximately 13) and the lowest (five) on diseased plants (Table 1). Every year, the highest number of clusters per plant was always observed on healthy plants, a lower number was present on the recovered ones, and the lowest was always recorded on the affected plants. No significant interaction between years and plant category was observed $(P=0.344)$.

A further two-way ANOVA was applied to study the yield of recovered plants based on time of recovery: the average number of clusters observed on recovered plants was not significantly different among years $(P=0.56)$ (Table 1$)$ nor did time elapsed from first recovery ( 1 to 5 years) significantly affect it $(P=0.78)$ (Table 2).

TABLE 1. Average number of fruit clusters per category of plant from 1999 to $2003^{z}$

\begin{tabular}{lccc}
\hline & \multicolumn{3}{c}{ Plant category } \\
\cline { 2 - 4 } Year & Healthy & Recovered & With symptoms \\
\hline 1999 & 15.4 & & 4.9 \\
2000 & 12.1 & 8.8 & 4.4 \\
2001 & 12.5 & 8.9 & 6.0 \\
2002 & 11.9 & 10.2 & 5.3 \\
2003 & 11.6 & 10.1 & 5.8 \\
Mean & $12.7 \mathrm{a}$ & $9.5 \mathrm{~b}$ & $5.3 \mathrm{c}$ \\
\hline
\end{tabular}

$\mathrm{z}$ The numbers of clusters were significantly different between categories $(P=$ 0.000 ) according to a factorial analysis of variance. The same letter indicates average values not significantly different according to the Tukey test at $P \leq$ 0.05 .

TABLE 2. Average number of fruit clusters on recovered plants from 2000 to 2003 and corresponding duration of recovery

\begin{tabular}{lrrrrr}
\hline & \multicolumn{3}{c}{ Year of observation } \\
\cline { 2 - 5 } Recovery duration (years) & 2000 & 2001 & 2002 & 2003 & Mean \\
\hline 1 & 8.6 & 7.6 & 10.7 & 9.4 & 9.1 \\
2 & 11.2 & 11.9 & 9.5 & 8.8 & 10.3 \\
3 & & 10.9 & 10.7 & 9.4 & 10.3 \\
4 & & & 10.0 & 10.2 & 10.1 \\
5 & & & & 8.9 & 8.9 \\
Mean & 9.9 & 10.1 & 10.2 & 9.3 & \\
\hline
\end{tabular}


The total number of $S$. titanus trapped each year in the seven vineyards is listed in Table 3. Two-way ANOVA showed a significant difference in the number of vectors trapped in different years and vineyards (Table 3 ). Numbers trapped decreased significantly from 1999 to 2000 (Table 3); in 2001 and 2002 the average number trapped (15 and 6 , respectively) was not significantly different. In 2003, the number trapped was significantly lower than in the previous years (Table 3). It was not possible to estimate the effect of interaction between years and vineyards because no replicates were available. However, differences between vineyards were observed in 1999 (Table 3) when trappings of S. titanus were highly variable from one vineyard to another (28 and 338 vectors trapped in vineyards S16 and S6 in 1999, respectively). In the following years, the pattern of trappings was very similar in all vineyards except S16; for this reason, since the point of interest was to study the pattern of trappings, vineyards were considered as replicates and average values per year were calculated.

Infection and recovery rates. The fit of the infection rate over time to equation 1 accounted for $96 \%$ of variability, standard errors of parameters were always lower than the parameter values, and the regression ANOVA was highly significant $(P=0.004)$ (Fig. 2). The infection rate decreased rapidly from the maximum observed in 1999 (1.6) to 0.14 in 2000 , then decreased to approximately 0 in 2003 .

If plotted against the ln-transformed number of vectors trapped in the vineyards in the previous year to take into account the incubation period of the disease, the infection rate increased from the lowest value corresponding to the lowest number of vectors and then increased rapidly as the number of vectors increased. This relationship was satisfactorily fitted $\left(R^{2}=0.95\right)$ by equation 2 (Fig. 3), having parameter standard errors lower than parameter values, a significant ANOVA, and a random distribution of residues against the dependent variable (not shown).

The recovery rate over time was satisfactorily fitted $\left(R^{2}=0.93\right)$ by equation 3 (Fig. 4). The relationship between the $\ln -$ transformed numbers of vectors trapped the preceding year and the corresponding recovery rate, as fitted by equation 4 , accounted for the $93 \%$ of the variability of the recovery rate and showed low values of parameter standard errors. The recovery rate reached maximum values following the lowest number of trapped vectors and then decreased as the presence of vectors increased (Fig. 5).

\section{DISCUSSION}

The assays showed that there was good correspondence between visual assessments and molecular diagnosis of FD. Disagreement between symptom assessment and PCR results occurred only when plants showed unevenly distributed symptoms. Absence of FD detection by PCR in a few symptomatic samples of partially symptomatic grapevines may be due to phytoplasma titre below the detection limit, as reported for grapevine (24) and other cultivated woody species under field conditions $(19,20)$.
Nevertheless, this aspect does not affect robustness of the results we obtained on the basis of visual assessment of symptomatic plants.

No BN infection was detected in the analyzed vines, although the disease is present in the area considered (23).

The numbers of newly infected and total FD-affected grapevines were similar in the different vineyards and in different years. This is in line with previous descriptions of FD incidence in the area following the epidemic in 1998/1999 (23). The total

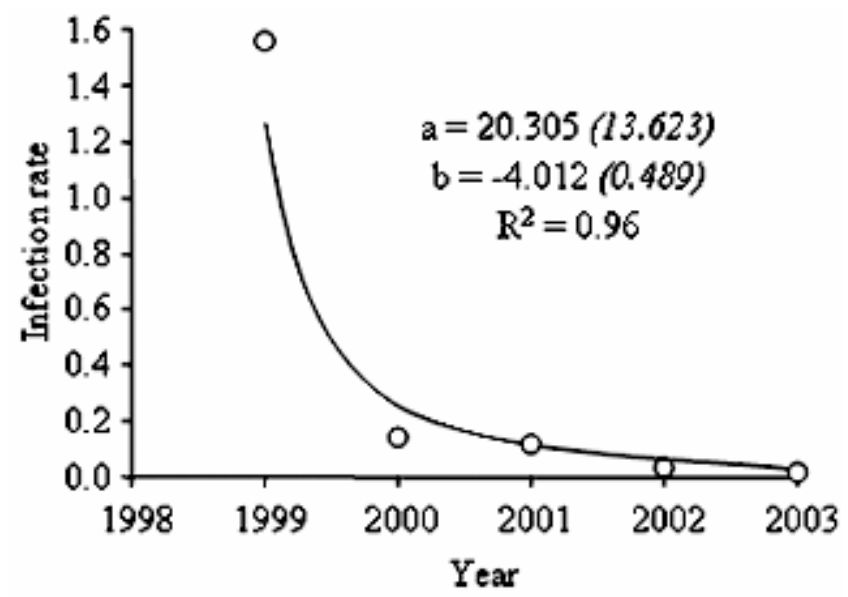

Fig. 2. Relationship of the average flavescence dorée infection over 5 years, estimated using equation 1. Points represent observed values; $a$ and $b$ are equation parameters and values in brackets are their standard errors. $R^{2}$ is the determination coefficient.

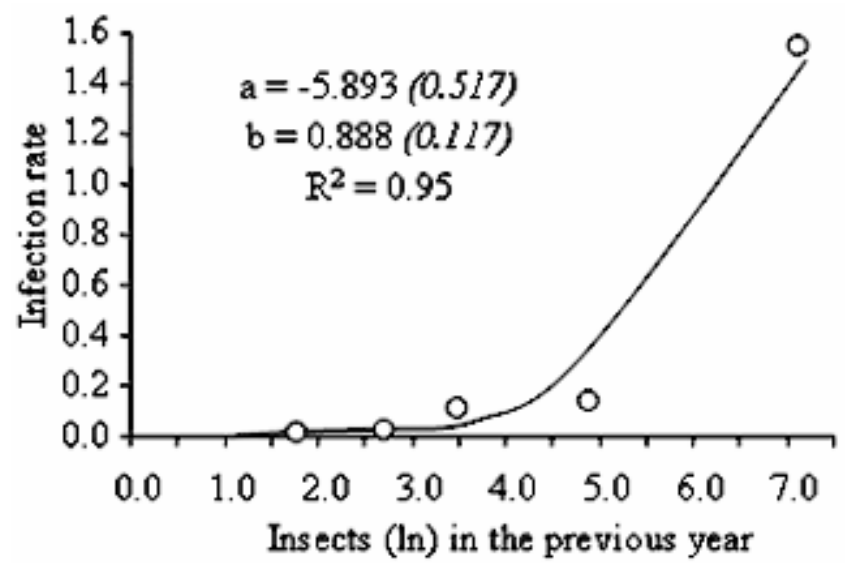

Fig. 3. Relationship between the average infection rate and logarithmic transformation of the average numbers of Scaphoideus titanus trapped in the vineyards the preceding year, estimated using equation 2. Points represent observed values; $a$ and $b$ are equation parameters and values in brackets are their standard errors. $R^{2}$ is the determination coefficient.

TABLE 3. Total number of Scaphoideus titanus trapped from 1999 to 2003 in seven vineyards ${ }^{\mathrm{z}}$

\begin{tabular}{|c|c|c|c|c|c|c|}
\hline Vineyard & 1999 & 2000 & 2001 & 2002 & 2003 & Mean \\
\hline $\mathrm{S} 2$ & 217 & 18 & 13 & 8 & 2 & $16.3 \mathrm{ab}$ \\
\hline $\mathrm{S} 3$ & 138 & 13 & 0 & 2 & 0 & $4.7 \mathrm{~b}$ \\
\hline S6 & 338 & 121 & 10 & 11 & 3 & $28.4 \mathrm{a}$ \\
\hline S9 & 103 & 13 & 5 & 5 & 1 & $9.1 \mathrm{ab}$ \\
\hline S11 & 73 & 7 & 1 & 1 & 0 & $3.7 \mathrm{~b}$ \\
\hline S13 & 34 & 9 & 4 & 2 & 1 & $6.4 \mathrm{~b}$ \\
\hline S16 & 28 & 47 & 71 & 12 & 6 & $24.7 \mathrm{a}$ \\
\hline Mean & $96.8 \mathrm{a}$ & $20.9 b$ & $6.8 \mathrm{c}$ & $5.5 \mathrm{c}$ & $2.3 \mathrm{~d}$ & \\
\hline Standard error & 42.10 & 15.60 & 9.52 & 1.71 & 0.80 & \\
\hline
\end{tabular}

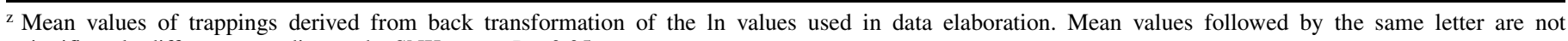
significantly different according to the SNK test at $P=0.05$. 
number of newly infected plants was highest in 1999. It is well known that severe FD symptoms generally appear on grapevines the year after inoculation. Monitoring of vector population started in 1999, and in that year, S. titanus populations were very high in six of the seven vineyards, the exception being vineyard S16. Following insecticide treatment, a lower level of vector control was recorded in vineyard S6, probably because of ineffective insecticide application. Nevertheless, the formulations used in the vineyards reduced the vector population approximately four to nine times in all vineyards except S16, where the number of trapped vectors increased between 1999 and 2001 and decreased from 2002, following the same pattern of reduction as the other vineyards. Absence of insecticide treatment or poor application methods can explain the increase in number of vectors trapped in the years 2000 and 2001. Moreover, vineyard S16 had the lowest number of trapped vectors in 1999 and this may have been the reason for a possible delay in the insecticide application. Re-colonization by $S$. titanus of the treated vineyard, from adjacent vineyards, may also explain the delay in reduction of the vector population in this vineyard, which lies at a distance of approximately $60 \mathrm{~km}$ from the other sites. Seasonal movement of $S$. titanus into the vineyards has been described in North America (3) and its flight activity has also been studied (16). Re-colonization by $S$. titanus of treated vineyards or hatching of eggs after insecticide treatment may explain the continued presence of $S$. titanus in the vineyards, even after 4 years of insecticide treatment.

The very good correlation between the infection rate and the ln of the average number of vectors trapped in the vineyards the preceding year indicates that in the vine varieties under observation, most FD infections (95\%) have a latent period of 1 year. This is in line with the epidemiology of FD-infected grapevines in northeastern Italy (29) and France (10), although this is the first model proposed describing this relationship. Longer latency of the disease in some vines may explain the low fraction of the infection rate (approximately 5\%) not correlated with S. titanus numbers trapped in the previous year. Latencies longer than 1 year have been reported on several occasions (30). Latency in trees infected with different phytoplasmas has been associated with a low phytoplasma titre in the host $(12,14)$, although no quantitative data are available to support this hypothesis in grapevine. Lack of symptoms during latency represents a serious problem in the vegetative propagation of woody hosts, such as grapevine.

The numbers of FD-recovered grapevines were similar every year in the different vineyards indicating that grapevine variety, among those in this study, did not affect the efficiency of recov-

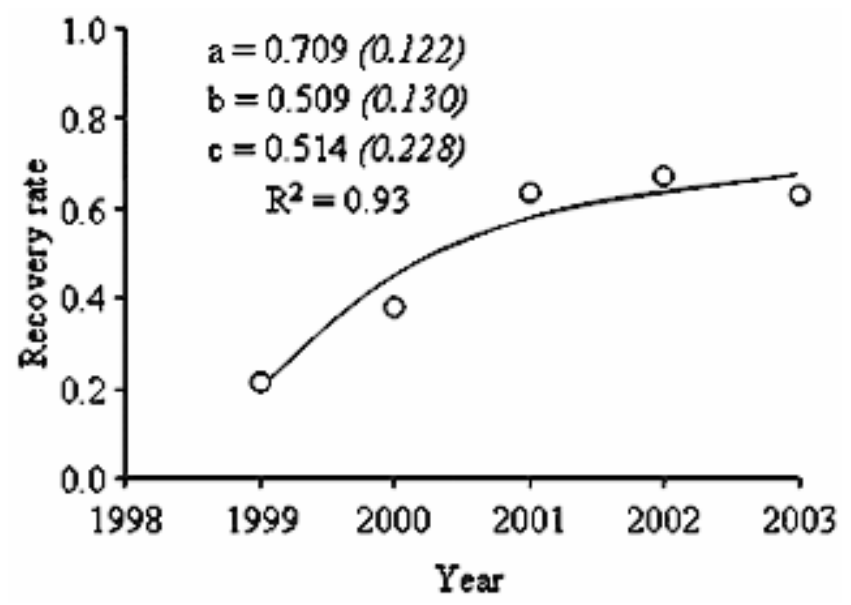

Fig. 4. Relationship of the recovery rate from 1999 to 2003, estimated using equation 3. Points represent observed values; $a, b$, and $c$ are equation parameters and values in brackets are their standard errors. $R^{2}$ is the determination coefficient. ery. Barbera, a typical Italian cultivar, has been reported as a cultivar showing high recovery phenotype when infected with FD, as have cvs. Baco 22 and Ugni blanc in France (10). In contrast, some Italian cultivars that are extremely sensitive to the disease do not recover from FD and continue to show symptoms each year until the plant dies $(10,29)$. Bonarda, Cortese and Dolcetto, the other cultivars studied here, are all typical of northwestern Italy and all showed good recovery. Recovery from FD was permanent, transient, and/or reversible, and for this reason, calculation of the recovery rate was a good tool to describe the trend of the phenomenon.

Permanent, transient, and/or reversible recovery has also been reported for $\mathrm{BN}$-infected vines. In most of these cases, the phytoplasma could not be detected, even after nested-PCR assays (29). Recovery has also been described for fruit trees affected with 'Candidatus Phytoplasma mali' and ' $\mathrm{Ca}$. Phytoplasma prunorum'. In both of these latter cases, however, the phytoplasma was still present in the symptomless tree, although confined to the root phloem in recovered apples (18). We did not detect FD phytoplasma in the canopy of recovered grapevines or even in the roots of heavily or partially FD-affected vines (not shown) in our nested-PCR assays. Phytoplasma infection also disappears from the canopies of recovered FD-infected cvs. Prosecco and Chardonnay, and $\mathrm{BN}$-infected cv. Pinot noir grapevines under field conditions in northeastern vineyards (29).

The recovery rate of FD-symptomatic grapevines we studied increased from 1999 to 2001 and remained around 0.7 over the last 2 years. Following insecticide application, the vector population decreased, but the remaining vectors were able to acquire the phytoplasma by feeding on the symptomatic grapevines always present. We suggest therefore, that the recovery rate we measured is an under-estimate because re-infections are probable. Symptoms localized to part of the canopy were ascribed by Caudwell et al. (10) to reinfection.

In most cases, we detected FDP in total DNAs extracted from symptomatic parts of partially affected plants but not from symptomless branches. In herbaceous hosts, following inoculation by the vector, the phytoplasma actively moves toward young developing organs $(17,31)$, but detailed studies on the colonization pattern of infected grapevines are not available.

The good negative correlation between the recovery rate and the ln of average $S$. titanus trapped in the vineyards the previous year underlines the need for good and continuous control of the vector to reduce reinfection of recovered vines. In the complete absence of further inoculation, obtained in a screenhouse, as much as $50 \%$ of $\mathrm{BN}$-infected grapevines showed a recovered phe-

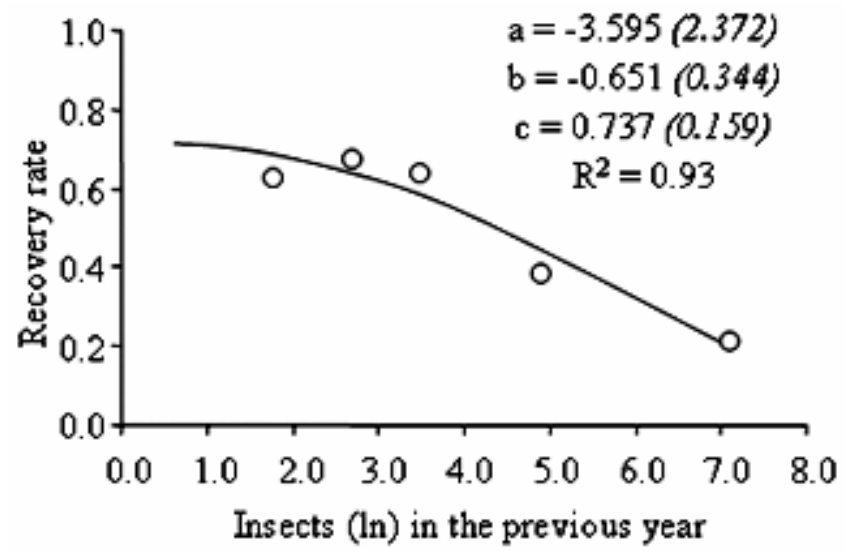

Fig. 5. Relationship between the average annual recovery rate and logarithmic transformation of the average number of Scaphoideus titanus trapped in the vineyards the preceding year, estimated using equation 4. Points represent observed values; $a, b$, and $c$ are equation parameters and values in brackets are their standard errors. $R^{2}$ is the determination coefficient. 
notype in the year of the transplantation and most of them remained symptomless for six consecutive years (28).

This is the first time that the effect of FD on productivity has been evaluated. Yields from recovered plants were always lower than that from healthy ones, irrespective of the length of the recovery up to the 5 years of observation. In any case, yield of recovered plants was always approximately $80 \%$ more than that of the symptomatic vines. Differences in the physiology of $\mathrm{BN}$ infected grapevines have been reported (5), and therefore, alterations in the physiology of the recovered vines may explain our results. It has already been reported that apple proliferation- and European stone fruit yellows-infected apple and apricot trees showing recovery have altered levels of some components of the oxygen-scavenging system as compared with healthy ones $(26,27)$.

$\mathrm{FD}$, besides being a quarantine disease, is a serious problem for viticulture in northwestern Italy. The presence of inoculum and vector in small, high quality vineyards has made control extremely difficult even in the presence of a law-enforced defense approach. Our results clearly indicate that recovery from FD infection occurs in grapevines grown under productive field conditions, although the mere absence of FD-specific PCR amplicons in total DNA extracts from recovered plants does not mean that the plant is indeed a poor source of phytoplasma for potential vectors. It has been reported that cultivars less sensitive to FD are a worse source of inoculum for the vector (6).

Our results also show that insecticide treatments coupled to planting cultivars showing high rates of recovery represent a possible management of the disease in northwestern Italy.

\section{ACKNOWLEDGMENTS}

This work was done as part of the Italian Regional Grant (Regione Piemonte) "Studi sulla flavescenza dorata della vite e sul suo vettore Scaphoideus titanus: epidemiologia, diagnostica, prevenzione, contenimento." Sub-project n. 1, and of the finalized Project: "Grapevine yellows" financed by the Italian Ministero delle Politiche Agricole e Forestali.

\section{LITERATURE CITED}

1. Alma, A., Davis, R. E., Vibio, M., Danielli, A., Bosco, D., Arzone, A., and Bertaccini, A. 1996. Mixed infection of grapevines in northern Italy by phytoplasmas including 16S rRNA RFLP subgroup 16SrI-B strains previously unreported in this host. Plant Dis. 80:418-421.

2. Angelini, E., Clair, D., Borgo, M., Bertaccini, A., and Boudon-Padieu, E. 2001. Flavescence dorée in France and Italy-Occurrence of closely related phytoplasma isolates and their near relationships to Palatinate grapevine yellows and an alder yellows phytoplasma. Vitis 40:79-86.

3. Beanland, L.A., Noble, R., and Wolf, T. K. 2006. Spatial and temporal distribution of North American grapevine yellows disease and of potential vectors of the causal phytoplasmas in Virginia. Environ. Entomol. 35:332344.

4. Belli, G., Fortusini, A., Osler, R., and Amici, A. 1973. Presenza di una malattia del tipo "Flavescence dorée" in vigneti dell'Oltrepò pavese. Riv. Patol. Veg. 9 S. IV (suppl):51-56.

5. Bertamini, M., Nedunchezhian, N., Tomasi, F., and Grando, M. S. 2002. Phytoplasma [Stolbur-subgroup (Bois Noir-BN)] infection inhibits photosynthetic pigments, ribulose-1,5-bisphosphate carboxylase and photosynthetic activities in field grown grapevine (Vitis vinifera L. cv. Chardonnay) leaves. Physiol. Mol. Plant Pathol. 61:357-366.

6. Bressan, A., Clair, D., Sémétey, O., and Boudon-Padieu, É. 2005. Effect of two strains of Flavescence dorée phytoplasma on the survival and fecundity of the experimental leafhopper vector Euscelidius variegatus Kirschbaum. J. Invertebr. Pathol. 89:144-149.

7. Caudwell, A. 1957. Deux années d'études sur la Flavescence dorée, nouvelle maladie grave de la vigne. Ann. Amelior. Plant. 4:359-393.

8. Caudwell, A. 1983. L'origine des jaunisses à mycoplasmes (MLO) des plantes et l'exemple des jaunisses de la vigne. Agronomie 3:103-111.

9. Caudwell, A. 1990. Epidemiology and characterization of Flavescence dorée (FD) and other grapevine yellows. Agronomie 10:655-663.

10. Caudwell, A., Boudon-Padieu, E., Kuszala, C., and Larrue, J. 1987. Biologie et étiologie de la Flavescence dorée. Recherches sur son diagnostic et sur les méthodes de lutte (Abstr.:175). Convegno sulla Flavescenza do- rata della vite.

11. Clewer, A. G., and Scarisbrick, D. H. 2001. Practical Statistics and Experimental Design for Plant and Crop Science. John Wiley and Sons, Chichester, UK.

12. Kison, H., and Seemuller, E. 2001. Differences in strain virulence of the European stone fruit yellows phytoplasma and susceptibility of stone fruit trees on various rootstocks to this pathogen. J. Phytopathol. 149:533-541.

13. Kunze, L. 1976. The effect of different strains of apple proliferation on the growth and crop of infected trees. Mitt. Biol. Bundesanst. LandFortwirtsch. Berl-Dahl. 170:107-115.

14. Lederer, W., and Seemuller, E. 1991. Occurrence of mycoplasma-like organisms in diseased and non-symptomatic alder trees (Alnus spp.). Eur. J. For. Pathol. 21:90-96.

15. Lee, I.-M., Gundersen, D. E., Hammond, R. W., and Davis, R. E. 1994. Use of mycoplasmalike organism (MLO) group-specific oligonucleotide primers for nested-PCR assays to detect mixed-MLO infections in a single host plant. Phytopathology 84:559-566.

16. Lessio, F., and Alma, A. 2004. Seasonal and daily movement of Scaphoideus titanus ball (Homoptera:Cicadellidae). Environ. Entomol. 33:1689-1694.

17. Lherminier, J., Courtois, M., and Caudwell, A. 1994. Determination of the distribution and multiplication sites of flavescence doree mycoplasma-like organisms in the host plant Vicia faba by ELISA and immunocytochemistry. Physiol. Mol. Plant Pathol. 45:125-138.

18. Loi, N., Ermacora, P., Ferrini, F., Carraio, L., and Osler, R. 2002. Tramissione sperimentale del fitoplasma degli scopazzi del melo da piante "recovered" e sintomatiche di melo. Petria 12:373-374.

19. Lorenz, K.-H., Schneider, B., Ahrens, U., and Seemuller, E., 1995. Detection of the apple proliferation and pear decline phytoplasmas by PCR amplification of ribosomal and nonribosomal DNA. Phytopathology 85:771776.

20. Marcone, C., Ragazzino, A., Del Serrone, P., Aloi, B., Barba, M., and Seemuller, E. 1996. Detection of apple proliferation and pear decline in Southern Italy. Petria 6:149-157.

21. Martini, M., Botti, S., Marcone, C., Marzachi, C., Casati, P., Bianco, P. A., Benedetti, R., and Bertaccini, A. 2002. Genetic variability among flavescence dorée phytoplasmas from different origins in Italy and France. Mol. Cell. Probes 16:197-208.

22. Marzachì, C., Alma, A., D’aquilio, M., Minuto, G., Boccardo, G. 1999. Detection and identification of Phytoplasmas infecting cultivated and wild plants in Liguria (Italian Riviera). J. Plant Pathol. 81:127-136.

23. Marzachì, C., Boarino, A., Vischi, A., Palermo, S., Morone, C., Loria, A., and Boccardo, G. 2001. Flavescenza dorata, legno nero e giallume dell' astro in vitigni del Piemonte sud orientale. Inf. Fitopatol. 9:58-63.

24. Marzachì, C., Palermo, S., Boarino, A., Veratti, F., d'Aquilio, M., Loria, A., and Boccardo, G. 2001. Optimisation of a one-step PCR assay for the diagnosis of flavescence dorée-related phytoplasmas in field grapevines and vector populations. Vitis 40:213-217.

25. Mori, N., Bressan, A., Martini, M., Guadagnini, M., Girolami, V., and Bertaccini, A. 2002. Experimental transmission by Scaphoideus titanus ball of two Flavescence dorée-type phytoplasmas. Vitis 41:99-102.

26. Musetti, R., Toppi, L. S., Ermacora, P., and Favali, M. A. 2004. Recovery in apple trees infected with the apple proliferation phytoplasma: An ultrastructural and biochemical study. Phytopathology 94:203-208.

27. Musetti, R., Toppi, L. S., Martini, M., Ferrini, F., Loschi, A., Favali, M. A., and Osler, R. 2005. Hydrogen peroxide localization and antioxidant status in the recovery of apricot plants from European stone fruit yellows. Eur. J. Plant Pathol. 112:53-61.

28. Osler, R., and Carraro, L. 1993. Symptom expression and disease occurrence of a yellows disease of grapevine in northeastern Italy. Plant Dis. 77:496-498.

29. Osler, R., Carraro, L., Ermacora, P., Ferrini, F., Loi, N., Loschi, A., Martini, M., Mutton, P. B., and Refatti, E. 2003. Roguing: A controversial practice to eradicate grape yellows caused by phytoplasmas. (Abstr.) ICVG Conf., 14th.

30. Osler, R., Zucchetto, C., Carraio, L., Frausin, C., Pavan, F., Vettorello, G., and Girolami, V. 2002. Trasmissione di flavescenza dorata e legno nero e comportamento delle viti infette. L'Informatore Agrario 19:61-65.

31. Saracco, P., Bosco, D., Veratti, F., and Marzachi, C. 2006. Quantification over time of Chrysanthemum yellows phytoplasma (16Sr-I) in leaves and roots of the host plant Chrysanthemum carinatum (Schousboe) following inoculation with its insect vector. Physiol. Mol. Plant Pathol. 67:212-219.

32. Schneider, B., Seemuller, E., Smart, C. D., and Kirkpatrick, B. C. 1995. Phylogenetic classification of plant pathogenic mycoplasmalike organisms or phytoplasmas. Pages 369-380 in: Molecular and Diagnostic Procedures in Mycoplasmology, Vol. 2. S. Razin and J. G. Tully, eds. Academic Press, New York.

33. Schvester, D., Carle, P., and Moutous, G. 1961. Sur la trasmission de la flavescence dorée des vigne par une cicadelle. C. R. Acad. Agric. Fr. 47:1021-1024. 